\title{
The Prevalence of Prediabetes in Sudanese Patients attending Khartoum North Teaching Hospital Referred Clinics Sudan
}

\author{
Abdelgader Suliman Ibrahim Ahmed ${ }^{1}$, Awadalla Mohammed Abdelwahid ${ }^{2}$, Maiada Abbas Albasha ${ }^{3}$ and \\ Siddig Omer Mohammed Handady ${ }^{4 *}$ \\ ${ }^{1}$ MD of internal Medicine Sudan, Sudan Medical Specialization Board (SMSB), Sudan
}

${ }^{2}$ Assistant professor of Obstetrics and Gynaecology, Faculty of Medicine, Al Neelan University, Sudan

${ }^{3}$ MD of Internal Medicine, Endocrinology and metabolism fellowship, Sudan Medical Specialization Board (SMSB), Sudan

${ }^{4}$ Consultant of Obstetrics and Gynaecology, Ibrahim Malik Hospital, Sudan

*Corresponding author: Siddig Omer Mohamed Handed, Consultant of obstetrics and gynaecology, Ibrahim Malik Hospital, Khartoum, Sudan.
Received Date: August 28, 2019

Published Date: October 03, 2019

\section{Abstract}

Background: Prediabetes is an important health issue which rarely draw health attention, and hence it is underestimated and under diagnosed. It is importance comes from the fact that it carries the same risk as Type 2 diabetes mellitus (T2DM) and the high potential risk to develop T2DM.

Objectives: To determine the prevalence of prediabetes, impaired glucose tolerance (IGT) and the risk factors that increase acquisition of T2DM in Khartoum North Teaching Hospital-Khartoum-Sudan

Material and Methods: It were descriptive cross-sectional hospital-based study carried out at Khartoum North Teaching Hospital-KhartoumSudan during the period September 2016 to April 2017. Four hundred participants above 40 years of age were incorporated. Data was collected by structure questionnaire. Fasting blood glucose and two hours postprandial was obtained by a finger puncture under aseptic conditions. World Health Organization criteria were adopted for the diagnosis of DM (fasting plasma glucose $\$ 7.8 \mathrm{mmol} \mathrm{L} 21$ or plasma glucose of $\$ 11.1 \mathrm{mmol} \mathrm{L} 21,2 \mathrm{~h}$ after an oral anhydrous glucose load of 75g) and IGT (fasting plasma glucose ,7.8mmol L21 and plasma glucose between $7.8 \mathrm{mmol} \mathrm{L} 21 \mathrm{and} 11.1 \mathrm{mmol}$ $\mathrm{L} 21,2 \mathrm{~h}$ after an oral glucose load of 75g). Ethical clearance and approval for conducting this research was obtained from the State Ministry of Health and the hospital and informed verbal consent was obtained from every respondent who agreed to participate in the study.

Results: During the study period; a total of 400 volunteers above 40 years were recruited. Among which the males were 195 (48.8\%) and the females were $205(51.2 \%)$. All the participants were investigated by fasting blood glucose and two hours postprandial. Hba1c was request for 27 patients (6.8\%) who showed impaired glucose for both fasting and two hours. The prevalence of prediabetes was $27(6.75 \%), 24(6.00 \%)$ has impaired GT, and $0.75 \%$ has IFG. Fasting blood glucose was found to be impaired in two patients whose age 51-60 year and in only one who was more than 60year, which is significant ( $\mathrm{p}$ value $=0.01$ ).

Conclusion: Almost low prevalence of prediabetes (6.75\%) among Sudanese citizens; housewife's women, population who have positive family history of DM, who are obese, who with no regular exercise and more than 60 years were at higher risk of prediabetes.

Keywords: Prediabetes; FBG; Prevalence; Risk factors; Khartoum State; Sudan

\section{Introduction}

Prediabetes (PDM) is an important health issue which rarely draw health workers attention, and hence it is underestimation and under diagnosis. It is an important health issue given the associated complications which are the same for type 2 diabetes mellitus(T2DM) and high rate for development T2DM. Unfortunately, there is no Sudanese studies has been published yet regarding prediabetes.
The first technical report for diagnostic criteria of Diabetes Mellitus was published by the World Health organization in 1965 [1]. "Borderline diabetes" and "Chemical Diabetes" were used to classify people with glucose levels in the non-diabetes range and had a higher risk of developing diabetes subsequently [2]. But the term impaired glucose tolerance (IGT) was first mentioned only in 1979 to include people who have plasma glucose between the 
diabetes range and the normal plasma glucose [3]. Again, IGT is recognized as a condition predisposing to T2DM but no further measures to manage this condition were described. It was not until 1999 that the term fasting plasma glucose (IFG) was introduced to explain the dysglycaemic fasting plasma glucose [4].

IFG and IGT have been interchangeably included under the conditions non-diabetic hyperglycaemia (NDH), impaired glucose regulation (IGR) and impaired glucose metabolism (IGM). It is recommended that the term PDM may be used to address the disorders of IGR when communicating to non-healthcare professionals [5]. However, PDM does not inevitably lead to T2DM [6]. PDM was recognized as a major healthcare problem in the late 90s and the early 2000 following publication of results of landmark prevention studies for T2DM. The aim of this study was to determine the prevalence of prediabetes and the risk factors that increase acquisition of T2DM in Khartoum North Teaching Hospital- Khartoum-Sudan.

\section{Material and Methods}

It was descriptive cross-sectional hospital-based study carried out at Khartoum North Teaching Hospital-Khartoum-Sudan during the period September 2016 to April 2017. Four hundred participants above 40 years of age were incorporated. Data was collected by structure questionnaire. Fasting blood glucose and two hours postprandial was obtained by a finger puncture under aseptic conditions. Those who were seriously ill or had recent history of hospitalization due to any ailments were excluded from the study. Demographic data, history or family history and treatment history of DM or hypertension as well as smoking habits and regular exercise were obtained from the participants by a structured questionnaire. The arterial blood pressure was measured using mercury sphygmomanometers. The American Heart Association Guidelines for In-Clinic Blood Pressure Measurement [4], were applied for the participants. Capillary blood glucose was obtained by a finger puncture under aseptic conditions to measure a fasting blood glucose and two hours postprandial.

The body mass index (BMI) is defined as the weight in kilograms divided by the square of the height in meters $\left(\mathrm{kg} / \mathrm{m}^{2}\right)$. The BMI was determined by using World Health Organization (WHO) classification for obesity [4]. For the purpose of this study, diabetes diagnosed as fasting blood glucose concentration more than $7 \mathrm{mmol}$ /litre or $>126 \mathrm{mg} / \mathrm{dl}$, impaired fasting glucose (IFG) is a fasting blood glucose between $110 \mathrm{mg}-125 \mathrm{mg}$ or $6.1 \mathrm{mmol}-6.9 \mathrm{mmol}$. Statistical analysis was performed via SPSS software (SPSS, Chicago, IL, USA). Continuous variables were compared using student's $t$ test (for paired data) or Mann-Whitney U test for non-parametric data. For categorical data, comparison was done using Chi-square test (X2) or Fisher's Exact test when appropriate. A P value of $<0.05$ was considered statistically significant.

Ethical clearance and approval for conducting this research was obtained from the State Ministry of Health and the hospital and informed verbal consent was obtained from every respondent who agreed to participate in the study. Of course, the respondents informed that the study is not associated with experimental or therapeutic intervention while information was collected from them.

\section{Results}

A total of 400 participants had both FPG and 2HPP measured. The mean age was $51.4 \pm 1.85$ years and the proportion of female participants was $51.2 \%$, majority were housewives $41.2 \%$ and illiterate $36.2 \%$. The mean BMI, $27.4 \pm 2.43 \mathrm{~kg} / \mathrm{m} 2$. Of the study population, (33.5\%) had positive family history of diabetes mellitus, only $(18.3 \%)$ were had positive family history of hypertensive. The prevalence of prediabetes was $27(6.75 \%), 24(6.00 \%)$ has impaired GT, and $0.75 \%$ has IFG. Fasting blood glucose test was normal in $(98.8 \%)$, impaired in $(0.75 \%)$, and in the range of diabetes in $(0.25 \%)$. Two hours post prandial was normal in $(92.75 \%)$, impaired in (6\%), and in diabetes range in (1.25\%) (Table 1).

Table 1: Demographic and clinical characteristics of the 400 participants ( $\mathrm{FH}=$ family history, $\mathrm{DM}=$ diabetes mellitus, $\mathrm{HTN}$ = systemic hypertension).

\begin{tabular}{|c|c|c|c|}
\hline \multicolumn{2}{|c|}{ Characteristics } & Frequency & Percentage \\
\hline sAge & $\begin{array}{c}40-50 \text { years } \\
51-60 \text { years } \\
\geq 60 \text { years } \\
\text { Total }\end{array}$ & $\begin{array}{l}156 \\
131 \\
113 \\
400\end{array}$ & $\begin{array}{c}39.0 \\
32.8 \\
28.2 \\
100.0\end{array}$ \\
\hline Sex & $\begin{array}{c}\text { Male } \\
\text { Female } \\
\text { Total }\end{array}$ & $\begin{array}{c}48.8 \\
51.2 \\
100.0\end{array}$ & $\begin{array}{c}48.8 \\
51.2 \\
100.0\end{array}$ \\
\hline Residence & $\begin{array}{c}\text { Khartoum } \\
\text { Outside Khartoum } \\
\text { Total }\end{array}$ & $\begin{array}{l}277 \\
123 \\
400\end{array}$ & $\begin{array}{c}69.2 \\
30.8 \\
100.0\end{array}$ \\
\hline Occupation & $\begin{array}{l}\text { Un employee } \\
\text { Worker } \\
\text { Housewife } \\
\text { Employee } \\
\text { Professional } \\
\text { Total }\end{array}$ & $\begin{array}{c}33 \\
119 \\
165 \\
75 \\
8 \\
400\end{array}$ & $\begin{array}{c}8.2 \\
29.8 \\
41.2 \\
18.8 \\
2.0 \\
100.0\end{array}$ \\
\hline Education & $\begin{array}{c}\text { Illiterate } \\
\text { Primary } \\
\text { Secondary } \\
\text { University \& above } \\
\text { Total }\end{array}$ & $\begin{array}{c}144 \\
108 \\
93 \\
55 \\
400\end{array}$ & $\begin{array}{c}36.0 \\
27.0 \\
23.2 \\
13.8 \\
100.0 \\
\end{array}$ \\
\hline $\begin{array}{c}\text { Family History of } \\
\text { DM }\end{array}$ & $\begin{array}{c}\text { Yes } \\
\text { No } \\
\text { Total }\end{array}$ & $\begin{array}{l}134 \\
266 \\
400\end{array}$ & $\begin{array}{c}33.5 \\
66.5 \\
100.0\end{array}$ \\
\hline $\begin{array}{c}\text { Family History of } \\
\text { HIN }\end{array}$ & $\begin{array}{l}\text { Yes } \\
\text { No } \\
\text { Total }\end{array}$ & $\begin{array}{r}73 \\
327 \\
400\end{array}$ & $\begin{array}{c}18.2 \\
81.8 \\
100.0\end{array}$ \\
\hline Smoking & $\begin{array}{c}\text { Yes } \\
\text { No } \\
\text { Total }\end{array}$ & $\begin{array}{c}30 \\
370 \\
400\end{array}$ & $\begin{array}{r}07.5 \\
92.5 \\
100.0\end{array}$ \\
\hline Regular Exercise & $\begin{array}{c}\text { Yes } \\
\text { No } \\
\text { Total }\end{array}$ & $\begin{array}{r}66 \\
334 \\
400\end{array}$ & $\begin{array}{c}16.5 \\
83.5 \\
100.0\end{array}$ \\
\hline BMI & $\begin{array}{l}\text { Underweight } \\
\text { Normal } \\
\text { Overweight } \\
\text { Obese } \\
\text { Total } \\
\end{array}$ & $\begin{array}{c}56 \\
117 \\
130 \\
97 \\
400\end{array}$ & $\begin{array}{c}14.0 \\
29.2 \\
32.5 \\
24.3 \\
100.0\end{array}$ \\
\hline FBG finding & $\begin{array}{l}\text { Normal } \\
\text { Impaired } \\
\text { DM } \\
\text { Total }\end{array}$ & $\begin{array}{c}395 \\
3 \\
2 \\
400\end{array}$ & $\begin{array}{c}98.8 \\
0.8 \\
0.4 \\
100.0 \\
\end{array}$ \\
\hline 2HPP finding & $\begin{array}{l}\text { Normal } \\
\text { Impaired } \\
\text { DM } \\
\text { Total }\end{array}$ & $\begin{array}{c}371 \\
24 \\
5 \\
400\end{array}$ & $\begin{array}{c}92.8 \\
6.0 \\
1.2 \\
100.0\end{array}$ \\
\hline
\end{tabular}


Among demographic characteristics, age, family History of DM, lack of exercise, and family history of HIN were associated with IFG (P-value $<0.05$ ) as in Table 2. Among clinical characteristics, prediabetes was associated with BMI, and positive family history of HIN (P-value $<0.05$ ) as in Table 2. The identified predicators of prediabetes are as follows: Age-when compared to the (40-50 years), the prevalence was higher among the age group of 51-65 years with.

Table 2: Risk factors associated with fasting blood glucose (FBG) levels.

\begin{tabular}{|c|c|c|c|c|}
\hline Parameter & $\begin{array}{c}\text { Normal } \\
\text { (395) }\end{array}$ & $\begin{array}{c}\text { Impaired } \\
\text { (3) }\end{array}$ & DM2 & $P$ value \\
\hline \multicolumn{5}{|c|}{ Age (years) } \\
\hline $40-50$ & $156(39.4 \%)$ & $0(0.0 \%)$ & $0(0.0 \%)$ & $0.01^{*}$ \\
\hline $51-<60$ & $127(32.2 \%)$ & $2(66.7 \%)$ & $2(100.0 \%)$ & \\
\hline$\geq 60$ & $112(28.4 \%)$ & $1(33.3 \%)$ & $0(0.0 \%)$ & \\
\hline \multicolumn{5}{|c|}{ Sex } \\
\hline Female & $201(50.9 \%)$ & $3(100.0 \%)$ & $1(50.0 \%)$ & 0.13 \\
\hline Male & $194(49.1 \%)$ & $0(0.0 \%)$ & $1(50.0 \%)$ & \\
\hline \multicolumn{5}{|c|}{ Education } \\
\hline Illiterate & $142(35.9 \%)$ & $2(66.7 \%)$ & $0(0.0 \%)$ & 0.46 \\
\hline Primary & $106(26.8 \%)$ & $1(33.3 \%)$ & $1(50.0 \%)$ & \\
\hline Secondary & $92(23.4 \%)$ & $0(0.0 \%)$ & $1(50.0 \%)$ & \\
\hline $\begin{array}{l}\text { University \& } \\
\text { above }\end{array}$ & $55(13.9 \%)$ & $0(0.0 \%)$ & $0(0.0 \%)$ & \\
\hline \multicolumn{5}{|c|}{ Family History of DM } \\
\hline Yes & $131(33.2 \%)$ & $2(66.7 \%)$ & $1(50.0 \%)$ & $0.01^{*}$ \\
\hline No & $264(66.8 \%)$ & $1(33.3 \%)$ & $1(50.0 \%)$ & \\
\hline \multicolumn{5}{|c|}{ Regular exercise } \\
\hline Yes & $66(16.7 \%)$ & $0(0.0 \%)$ & $0(0.0 \%)$ & $0.00^{*}$ \\
\hline No & $329(83.3 \%)$ & $3(100.0 \%)$ & $2(100.0 \%)$ & \\
\hline \multicolumn{5}{|c|}{ History of HIN } \\
\hline Yes & $70(17.7 \%)$ & $3(100.0 \%)$ & $0(0.0 \%)$ & $0.00^{*}$ \\
\hline No & $325(82.3 \%)$ & $0(0.0 \%)$ & $2(100.0 \%)$ & \\
\hline \multicolumn{5}{|c|}{ Body mass index } \\
\hline Underweight & $56(14.1)$ & $0(0.0)$ & $0(0.0)$ & $0.01^{*}$ \\
\hline $\begin{array}{l}\text { Normal } \\
\text { weight }\end{array}$ & $116(29.4)$ & $0(0.0)$ & $0(0.0)$ & \\
\hline Overweight & $128(32.4)$ & $1(33.3)$ & $1(50.0)$ & \\
\hline Obese & $95(24.1)$ & $2(66.7)$ & $0(0.0)$ & \\
\hline \multicolumn{5}{|c|}{ Occupation } \\
\hline Unemployee & $33(08.4)$ & $0(0.0)$ & $0(0.0)$ & 0.25 \\
\hline Worker & $117(29.6)$ & $0(0.0)$ & $2(100.0)$ & \\
\hline Housewife & $162(41.0)$ & $3(100.0)$ & $0(0.0)$ & \\
\hline Employee & $75(19.0)$ & $0(0.0)$ & $0(0.0)$ & \\
\hline Professional & $8(02.0)$ & $0(0.0)$ & $0(0.0)$ & \\
\hline
\end{tabular}

Educational level the prevalence was high in illiterates, primary school, and absent in secondary or university education Within the family history, those who have family history have significantly higher prevalence of prediabetes. In clinical characteristics, the prevalence was significantly higher among participants with high BMI (overweight and obese) compared to normal Table $2 \& 3$ shows risk factors associated with 2 hour post prandial (2HPP) levels, impaired 2HPP was associated with age, sex, level of education, family History of DM, lack of exercise, family history of HIN and high BMI (P-value $<0.05)$.

Table 3: Risk factors associated with 2hours post prandial (2HPP) levels.

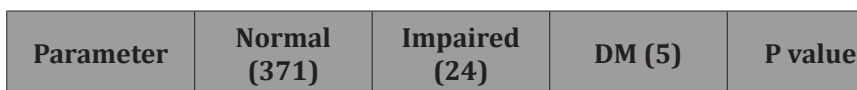

\begin{tabular}{|c|c|c|c|c|}
\hline \multicolumn{5}{|c|}{ Age (years) } \\
\hline $40-50$ & $151(40.7 \%)$ & $5(20.8 \%)$ & $0(0.0 \%)$ & $0.00 *$ \\
\hline $51-<60$ & $111(29.9 \%)$ & $15(62.5 \%)$ & $5100.0 \%)$ & \\
\hline$\geq 60$ & $109(29.4 \%)$ & $4(16.7 \%)$ & $0(0.0 \%)$ & \\
\hline
\end{tabular}

\begin{tabular}{|c|c|c|c|c|}
\hline \multicolumn{4}{|c|}{ Sex } \\
\hline Female & $188(50.7 \%)$ & $5(20.8 \%)$ & $2(40.0 \%)$ & $0.01^{*}$ \\
\hline Male & $183(49.3 \%)$ & $19(79.2 \%)$ & $3(60.0 \%)$ & \\
\hline Education & & & & \\
\hline Illiterate & $135(36.4 \%)$ & $9(37.5 \%)$ & $0(0.0 \%)$ & $0.00^{*}$ \\
\hline Primary & $91(24.5 \%)$ & $15(62.5 \%)$ & $2(40.0 \%)$ & \\
\hline Secondary & $92(24.8 \%)$ & $0(0.0 \%)$ & $1(20.0 \%)$ & \\
\hline $\begin{array}{c}\text { University \& } \\
\text { above }\end{array}$ & $53(14.3 \%)$ & $0(0.0 \%)$ & $2(40.0 \%)$ & \\
\hline
\end{tabular}

\begin{tabular}{|c|c|c|c|c|}
\hline \multicolumn{5}{|c|}{ Family History of DM } \\
\hline Yes & $124(33.4 \%)$ & $5(20.8 \%)$ & $5(100.0 \%)$ & $0.00^{*}$ \\
\hline No & 247 (66.6\%) & $19(79.2 \%)$ & $0(0.0 \%)$ & \\
\hline \multicolumn{5}{|c|}{ Regular exercise } \\
\hline Yes & $66(17.8 \%)$ & $0(0.0 \%)$ & $0(0.0 \%)$ & $0.00^{*}$ \\
\hline No & $305(82.2 \%)$ & $24(100.0 \%)$ & $5(100.0 \%)$ & \\
\hline \multicolumn{5}{|c|}{ History of HIN } \\
\hline Yes & $61(16.4 \%)$ & $12(50.0 \%)$ & $0(0.0 \%)$ & $0.00^{*}$ \\
\hline No & $310(83.6 \%)$ & $12(50.0 \%)$ & $5(100.0 \%)$ & \\
\hline \multicolumn{5}{|c|}{ Body mass index } \\
\hline Underweight & $52(14.0 \%)$ & $3(12.5 \%)$ & $1(20.0 \%)$ & $0.00^{*}$ \\
\hline $\begin{array}{l}\text { Normal } \\
\text { weight }\end{array}$ & $106(28.6 \%)$ & $8(33.3 \%)$ & $3(60.0 \%)$ & \\
\hline Overweight & $124(33.4 \%)$ & $5(20.9 \%)$ & $1(20.0 \%)$ & \\
\hline Obese & $89(24.0 \%)$ & $8(33.3 \%)$ & $0(0.0 \%)$ & \\
\hline \multicolumn{5}{|c|}{ Occupation } \\
\hline Unemployee & $33(08.9)$ & $0(0.0)$ & $0(0.0)$ & $0.00 *$ \\
\hline Worker & $114(30.7)$ & $0(0.0)$ & $5(100.0)$ & \\
\hline Housewife & $146(39.4)$ & $19(79.2)$ & $0(0.0)$ & \\
\hline Employee & $70(18.9)$ & $5(20.8)$ & $0(0.0)$ & \\
\hline Professional & $8(02.1)$ & $0(0.0)$ & $0(0.0)$ & \\
\hline
\end{tabular}

\section{Discussion}

Prediabetic individuals are at increased risk for developing micro vascular and macro vascular complications prior to diagnosis , so diagnosis of pre diabetes is a good opportunity to identify patients at increased risk for type 2 diabetes and to implement interventions that can delay or prevent type 2 diabetes and its complication, unfortunately this opportunity is often unrecognized by health-care providers. Our study find that, among those investigated 373 (93.25\%) were normal, 27 (6.75\%) had impaired glucose regulation, of them, IFG was in $3(0.75 \%)$, and $2 \mathrm{HPP}$ was impaired in $24(6.0 \%)$, all 27 patients of impaired glucose 
regulation requested to do $\mathrm{HbA1c}$, just seven of them showed up with the result, all were below $6.5 \%$, i.e. normal.

Also, there were two fasting blood glucose results in the diabetes range, and five members has diabetic range when they investigated by blood glucose level after two hours 2HPP test. All had been counselled about their blood glucose status. The main results of the current study are the low prevalence of pre- diabetes (6.75\%), housewife's women, those who have positive family history of DM, who are obese, who with no regular exercise and more than 60 years were at higher risk of prediabetes. This was a hospital-based study and most Sudanese people go to primary health centre. This could explain the relatively low prevalence of prediabetes in our study.

Our data demonstrate a prevalence rate of pre diabetes (6.75\%), $24(6.00 \%)$ has impaired GT (2HPP) and $0.75 \%$ has IFG which it is comparable with the global prevalence of IGT $8.3 \%$ [16] , but was lower than that reported from most countries in the region $[7,8]$. A comparison of our data with these reports is difficult because of the different criteria used, the different age groups studied, and the different methodologies adopted. The difference between our study and other studies may be explained by multiple factors such as, the differences in environmental risk factors, genetic, socioeconomic factors, prevalence of other associated risk factors for prediabetes and the method of blood glucose determination. In this study, the majority of cases of IGR were housewives (41.0\%) of them $3(100.0 \%)$ had IFG and $19(70.3 \%)$ had IGT, there were $5(18.5 \%)$ employees had IGR all has IGT, this shows a relation between decreased physical activity and IGR which is consistent with a study in Turkey by Kelestimur F et al, which showed similar result [9].

In the present study, females were more likely to have impaired fasting blood glucose than males. Previous reports were variable regarding gender differences in the prevalence of prediabetes. Our data are consistent with those reported from Iraq [10] and AbuDhabi [11]. As we are going through the other risk factors, we find that (55.8\%) of our populations have high body mass index ranging from overweight to obese and the study demonstrate strong association between BMI and prediabetes (P value 0.02).

Moreover, the current study reveals that, there was statistically significant difference in the prevalence of prediabetes between normal weight and overweight or obese population, the prevalence of IFG and I 2HPP was higher amongst overweight and obese subjects. This finding has been reported by previous studies which states that (Obesity, mainly central obesity has long been considered a risk factor for prediabetes DM and other cardiovascular diseases)
$[7,12]$. Lack of regular exercise and bad dietary habit can be others risk factors for insulin resistance.

The present study finds that $(82.2 \%)$ of our study population has no regular exercise program as most of them are females in addition to cultural aspect. This is in keeping with other studies $[13,14]$. Based on genetics, family history of diabetes is a strong factor for development of IFG even in the absence of obesity [15]. In the present study, prevalence of prediabetes was higher among positive family history of DM.

\section{Strength and limitation of this study}

The strength of this study, data was collected by structure questionnaire. Fasting blood glucose and two hours postprandial was obtained by a finger puncture under aseptic conditions. World Health Organization criteria were adopted for the diagnosis of DM (fasting plasma glucose $\$ 7.8 \mathrm{mmol}$ L21 or plasma glucose of $\$ 11.1 \mathrm{mmol}$ L21, $2 \mathrm{~h}$ after an oral anhydrous glucose load of $75 \mathrm{~g}$ ) and IGT (fasting plasma glucose, $7.8 \mathrm{mmol} \mathrm{L21}$ and plasma glucose

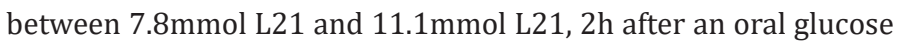
load of $75 \mathrm{~g}$ ).This study had some limitations. The relatively few number of study participants, may affect negatively the probability of finding significant relationships between different factors or variables with the IGR.

Other limitation of the present study was confounded by inadequate sample size or selection bias. Small sample size is open to a beta-II type error: a failure to accurately identify a true difference (i.e., a false negative result). In spite of limitations like small sample size and uncentre model, this study takes an important step towards exploring the inter-relationship of various predictors for prediabetes and impaired glucose tolerance.

\section{Conclusion}

Almost low prevalence of prediabetes (6.75\%) among Sudanese population, housewives' women, those population who have positive family history of DM, who are obese, who with no regular exercise and more than 60 years were at higher risk of prediabetes. Considering the low prevalence of this sickness makes it imperative to formulate a national plan to face this disease and its complications.

\section{Acknowledgement}

None.

\section{Conflict of Interest}

None. 